\title{
Aroma e sabor no jardim
}

\author{
SONJA DE CASTRO BOECHAT(1)
}

\begin{abstract}
RESUMO
As plantas que contêm óleo essencial são conhecidas como plantas aromáticas. Têm amplo uso na condimentação de alimentos, propiciando combinações inigualáveis às receitas, sejam elas salgadas ou doces. Arbóreas, arbustivas, herbáceas e trepadeiras com tais características são apresentadas, com ênfase em seu uso na culinária. Breves considerações são feitas sobre os constituintes ativos que lhes dão aroma e sabor e sobre a colheita, secagem e armazenamento adequados de forma a preservá-los. A sua propagação e o correto cultivo, além do controle natural de pragas são, igualmente, abordados. Cultivadas de forma criativa, em espaços limitados ou mais amplos, podem formar agradáveis recantos.
\end{abstract}

Palavras-chave: plantas aromáticas, condimentos, cultivo, floreiras, espaços criativos.

\section{ABSTRACT \\ Aroma and flavor in the garden}

Plants which contain essential oil are known as aromatic plants. They are widely used in food seasoning, allowing superb combination in recipes, whether in confection or dinner plates. Arboreal, shrubby, herbaceous and creeping plants with such characteristics are presented, with a focus on their culinary use. Quick references are made about their active components which confer aroma and flavor to them, their adequate harvest, drying and storage in order to be preserved. Their propagation and correct growing, besides the natural plague control are equally approached. Grown in a creative way, whether in limited spaces or wider ones, they can produce pleasant spots.

Keywords: Aromatic plants, condiments, growing, flower beds, creative spaces.

Esta palestra foi planejada tendo em vista o tema do $\mathrm{V}$ Simpósio Internacional de Paisagismo que trata dos "Sentidos" e o claro interesse que, na atualidade, as ervas aromáticas e as especiarias voltam a despertar.

As plantas que contêm óleo essencial são conhecidas como plantas aromáticas. Têm amplo uso na condimentação doméstica e industrial de alimentos. Propiciam combinações inigualáveis às receitas, sejam elas salgadas ou doces. Podem tornar a degustação de um prato comum em um verdadeiro prazer - pelo aroma e sabor - despertando o interesse pelo conhecimento e uso dos condimentos na gastronomia.

Ervas, no contexto desta palestra, são plantas cujo caule não possui características lenhosas e das quais se utilizam as folhas e hastes, e às vezes as flores, como alimento ou como medicinal, por seu sabor e perfume e outras características. Tendem ao sabor silvestre. De um modo geral, procedem das zonas temperadas.

Eram usadas em ritos mágicos, na medicina, para perfumar as casas e as ruas, para tingir a roupa, para a elaboração de cosméticos e na cozinha. Os monastérios contavam com jardins medicinais. Mais adiante, os proprietários de casas de campo e os aldeãos passaram a cultivar ervas, seguindo-se ao longo do século XVIII o interesse pelo emprego das mesmas até o final do século XIX, quando começaram a ser utilizados, cada vez com maior freqüência, os medicamentos obtidos mediante síntese química.

$\mathrm{O}$ interesse pelo sistema de vida natural e pela alimentação sadia tem levado os consumidores a uma reação contra os corantes artificiais e os aditivos químicos empregados nos alimentos e, conseqüentemente, à procura pelos sabores naturais. Embora muitas ervas de uso culinário sejam hoje disponíveis em forma seca ou fresca por fornecedores comerciais, as ervas colhidas na hora têm um sabor incomparável. As pessoas procuram o prazer de cultivá-las, seja em espaços limitados como floreiras, balcões iluminados e vasos junto à janela, seja em espaços mais amplos. Estes espaços não precisam ser escondidos nos fundos do quintal. Ao contrário, podem formar agradáveis recantos, com bancos rodeados por odores peculiares, freqüentemente percebidos nos meandros da memória e que evocam momentos passados.

As especiarias são consideradas substâncias picantes ou aromáticas empregadas para dar sabor à comida. São geralmente obtidas dos caules, sementes, e frutos de plantas lenhosas e têm forte sabor. Boa parte das especiarias é originada dos países asiáticos tropicais. Entre elas a canela do Ceilão, a curcuma, a noz-moscada e o macis. As regiões tropicais americanas produzem a pimenta inglesa, a baunilha e o chili. Os países que bordejam o Mediterrâneo proporcionam o coentro, a mostarda o açafrão.

$\mathrm{Na}$ antiguidade, o seu uso na culinária devia ser o menos

(1)Bióloga, doutora em Botânica (UFRGS, Porto Alegre), professora de Jardinagem em Cursos de Extensão (UNISINOS - São Leopoldo, RS e UNIFRA - Santa Maria, RS), bem como no SENAR-RS, e de Botânica em Cursos de Paisagismo. sonjaboechat@uol.com.br 
importante. Eram empregadas para embalsamar, fumigar e obter ungüentos. Também para a obtenção de incenso, perfumes, produtos medicinais e cosméticos. Na época romana, seu uso culinário começou a ser difundido. Uma de suas principais funções era a de ocultar o odor que desprende da carne em mal estado e a de conservar. No século XIV, as especiarias possuíam importância vital para os boticários. Grande valor lhes era dado na aromatização de certas bebidas e dos alimentos. O afã de encontrar as especiarias em abundância inspirou viagens de exploração que resultaram nos grandes descobrimentos dos séculos XV e XVI e no desenvolvimento do comércio em escala mundial.

Plantas aromáticas, com períodos de vida mais curtos ou mais longos e com diferentes portes, podem integrar-se em um projeto paisagístico.

As plantas anuais, como o endro, e as bienais, como o funcho e o aipo, são caracterizadas pelo período de vida curto, enquanto as plantas perenes, como a sálvia e o alecrim, continuam o seu desenvolvimento após a floração, voltando a florescer outras vezes.

Árvores e arvoretas, arbustos, ervas e trepadeiras são formas vegetais que podem compor a lista de plantas, cuja característica peculiar é o aroma que exalam no jardim e o sabor que propiciam na cozinha. As três primeiras desenvolvem caules com considerável diâmetro. No contexto desta palestra, a canela, o cravo, o louro, o anis estrelado, o alecrim, a alcaparra e o zimbro são exemplos. As ervas, em geral, apresentam caule do tipo haste, verde e sem crescimento em espessura. São exemplos o orégano, a hortelã, o anis ou erva-doce e o funcho. As trepadeiras se enrolam sobre um suporte ou apresentam estruturas que as prendem, enquanto se desenvolvem. São exemplificadas pela pimenta preta e pela baunilha, a última uma orquídea terrestre.

Ao apresentar algumas plantas que têm aroma e cujo sabor é fundamental na cozinha, cabe enfatizar, além de seu aspecto, as partes utilizadas com importância econômica, sejam subterrâneas (raízes, rizomas, bulbos), sejam aéreas (casca de caule, folhas, flores, frutos e sementes).

As raízes são responsáveis pela fixação do vegetal no solo, absorção e condução da água e sais minerais. Outra função é o armazenamento de reservas nutritivas, o que ocorre em raízes tuberosas, como as da raiz forte.

Os caules, parte aérea da planta, sustentam folhas, flores e frutos. Haste é o caule delicado, não lenhoso das ervas, como a haste da manjerona e da sálvia. Tronco é o caule da maioria das árvores e arbustos. Em árvores, em geral apresenta fuste bem desenvolvido até o aparecimento das primeiras ramificações. É o que se observa no cravo da Índia, noz-moscada e canela do Ceilão. Caules dos tipos rizoma, freqüentemente horizontal e subterrâneo, como do gengibre e da curcuma, ou tipo bulbo, como da cebola e do alho, exemplificam o uso na culinária de partes vegetais subterrâneas ricas em reservas. A casca do caule é formada por várias camadas; fende-se e acaba por soltar-se. A canela do Ceilão é uma árvore da qual se retira a casca dos brotos e dos ramos de menor diâmetro. A casca externa é separada da interna. Após secas, as tiras de casca são atadas.

As folhas são geralmente verdes e têm como função realizar a fotossíntese. Se coloridas, enriquecem o paisagismo. São inúmeras as ervas aromáticas cujas folhas trazem sabor e aroma aos alimentos. Entre elas, a alfavaca, manjerona, menta, sálvia, louro, salsa e estragão.

As flores são constituídas pelas sépalas, pétalas, androceu (peças masculinas, os estames, onde está o pólen), gineceu (peças femininas, os pistilos, cuja porção superior capta o pólen). Na base do pistilo está o ovário que se transformará em fruto, após a fecundação dos óvulos; estes se transformarão em sementes. Nas sementes encontra-se o embrião. Botões florais, antes de se abrirem, cujo uso é freqüente na alimentação podem ser representados pelo cravo e a alcaparra. Em cultivo não chegam a completar a floração. Apenas partes florais podem ser utilizadas, como é o caso das partes superiores do pistilo do açafrão, razão pela qual, seu custo é tão elevado.

Os frutos podem ser secos, como os da noz-moscada e baunilha ou podem ser carnosos como os frutos das pimentas, páprica, pimenta chili e pimentão. Os frutos das plantas pertencentes à Família Apiaceae têm dois carpelos ou mericarpos, com condutos oleíferos que propiciam aroma acentuado. Os mericarpos se separam um do outro e têm aspecto tão semelhante a sementes que, popularmente, é dado a eles esse nome. As ditas "sementes" são usadas como aromatizantes. São exemplos o anis, a alcarávia (Kümmel), o coentro, o cominho, o aneto, o aipo e o funcho.

A semente é o óvulo desenvolvido após a fecundação, contendo o embrião. As sementes de gergelim, papoula, cardamomo e da mostarda estão entre as sementes aromáticas muito apreciadas. As sementes de cardamomo são vendidas dentro de suas cápsulas naturais que as protegem e devem ser retiradas. Estrutura especial- o arilo - pode aparecer na superfície de sementes. A semente da noz-moscada é parda, brilhante, coberta por um arilo (fonte do macis), de cor vermelha brilhante. A amêndoa da semente constitui a nozmoscada comercial. O arilo é separado da semente e deixado secar, adquirindo uma cor parda amarelecida. A germinação da semente corresponde ao desenvolvimento do embrião, início de uma nova vida.

Os óleos essenciais são uma mistura complexa de componentes voláteis, sendo na maioria das vezes, constituídos por moléculas de natureza terpênica. Alguns óleos essenciais mais conhecidos são o mentol, citral, cânfora, eugenol, geraniol, cumarina, vanilina, timol. Na sua composição encontram-se inúmeras substâncias, algumas em maior concentração, as quais caracterizam o aroma. A influência das variedades culturais, da natureza do terreno e do clima sobre o teor dos óleos revela-se em exemplos, como as essências comerciais de hortelã-pimenta. A luz solar favorece a formação do óleo.

Os óleos essenciais têm efeitos fisiológicos variados. As plantas que os apresentam podem ser cultivadas em jardins e usadas para chás saborosos, o que também interessa aos apreciadores de ervas aromáticas. Entre outras, o gengibre estimula secreções do aparelho digestivo, o funcho expulsa o ar gastrointestinal, a erva-doce suprime cólicas, o tomilho é expectorante.

As substâncias que dão os aromas aparecem em estruturas secretoras externas e internas. As externas fazem parte da 
epiderme ou são modificações desta, como os pêlos glandulares em pétalas de rosas, estigmas e estiletes do açafrão e em folhas do orégano. As estruturas internas se formam quando o óleo se acumula entre as células do tecido parenquimático que podem se diferenciar em glândulas. Canais oleíferos - ductos alongados contendo secreção produzida por células que os revestem - ocorrem em folhas da salsinha e nos frutos do funcho. Células secretoras especializadas, dispersas entre outras menos especializadas, ocorrem em folhas do louro e casca da canela.

Os óleos essenciais têm como funções nas plantas a atração de polinizadores, inclusive noturnos e a proteção contra ataque de animais por seu efeito irritante. Ocorrem em Gramíneas e Zingiberaceae, Rutaceae, Lauraceae, Lamiaceae, Asteraceae, Apiaceae, Myrtaceae e outras famílias. Estão presentes em muitas coníferas. Dentre estas, o zimbro produz 'bagas' utilizadas na aromatização do gim.

$\mathrm{Na}$ impossibilidade de se obter as ervas frescas - apesar de que a cada dia lhes é dada maior importância nos supermercados e feiras - elas podem ser utilizadas secas. A colheita, secagem e armazenamento devem ser adequados de forma a preservá-las.

Podem-se colher as ervas condimentares para uso das folhas em qualquer estágio da planta. Porém, de preferência no início da floração, quando os óleos essenciais alcançam a máxima concentração. Diferentemente, o alecrim, o tomilho e a menta têm mais aroma em plena floração. Entre outras recomendações, o estragão, alecrim, orégano, a hortelãpimenta e a sálvia são plantas perenes, utilizadas muitas vezes, devendo receber cuidado especial, de forma a não danificar desnecessariamente ramos e raízes; podem sofrer cortes severos, deixando-se uns 10 a $15 \mathrm{~cm}$ das hastes para novos rebrotes. Plantas com doenças, atacadas por insetos ou com manchas foliares deverão ser evitadas. As rasteiras, bem como raízes e rizomas devem ser lavados rapidamente em água corrente para retirar a terra aderida. Não se espera plena maturação dos frutos quando vão ser colhidos, pois há risco de perdê-los; é o que ocorre com o funcho. O teor de alcalóides e óleos essenciais é maior no período da manhã; já o teor de glicosídeos é maior no período da tarde. Assim, de acordo com o tipo de princípio ativo de uma planta, pode-se planejar o horário da colheita.

A secagem tem por finalidade reduzir a ação das enzimas, permitindo a conservação das plantas por mais tempo. O local deve ser sombreado, arejado e seco; a luz direta acelera a decomposição, alterando cor, sabor e odor. As plantas devem ser separadas entre si para evitar mistura de odores. Podemse pendurar pequenos feixes. Grelhas podem ser utilizadas. Giacometti (1989) recomenda caixas de madeira, com altura máxima de $15 \mathrm{~cm}$ e fundo de tela de náilon $\mathrm{Se}$ as caixas forem empilhadas, deve-se deixar um espaço de pelo menos um centímetro entre elas, para garantir a circulação do ar. Em uma semana as folhas estarão uniformemente secas, dependendo da espécie, da umidade do ar e da temperatura. A secagem excessiva poderá resultar em material pulverulento. Após a secagem, para a conservação caseira, retiram-se cuidadosamente as folhas dos ramos evitando-se quebrá-las, pois as folhas inteiras conservam melhor o aroma. Conservam- se em vidros escuros ou recipientes bem tapados de plástico. Sacos de tecidos não são recomendados, pois haverá a troca de odores.

Ervas delicadas, como a manjerona, a cebolinha, a salsa e o estragão podem ser congelados. Os pequenos feixes são mergulhados por meio minuto em água fervendo, o que inativa as enzimas oxidativas existentes e que poderão causar alterações no produto. Este tratamento contribui também para melhorar a fixação da cor. Em seguida, os feixes são esfriados rapidamente em água gelada, escorridos e embalados para congelamento.

Em geral, as ervas aromáticas são cultivadas em solos férteis, bem drenados e não toleram solos ácidos. O correto cultivo, a rega e a nutrição devem ser observados. As mudas crescem e rebrotam rapidamente. Por isso, às vezes, é preciso fazer uma poda, retirando as ervas que estão invadindo o espaço de outras plantas.

Entre outras considerações sobre o cultivo, as seguintes devem ser observadas quando estas plantas são empregadas em jardins. O poejo desenvolve-se em solo úmido e rico em matéria orgânica. $\mathrm{O}$ alecrim não suporta excesso de água; é indicado para jardins de xerófitas. O tomilho também não gosta de umidade; o ideal é plantá-lo em jardins rupestres e entre placas de pavimentação ou em áreas inclinadas. A sálvia, de cor acinzentada e aspecto aveludado, originária de regiões secas e pedregosas do sul da Europa, pode igualmente ser utilizada em jardim rochoso. Existem variedades de sálvia, inclusive de folhas arroxeadas, o que permite criar um mosaico colorido.

O funcho gosta de locais com luz solar direta; não resiste a geadas fortes. $\mathrm{O}$ estragão francês necessita de meia sombra e sofre com as chuvas. A alcarávia ou cominho, também conhecida como Kümmel, pouco freqüente no Brasil, também prefere condições semi-sombreadas. Segundo Giacometti (1989), as melhores condições climáticas para o cultivo de alcarávia são as do inverno do centro-sul, em altitudes elevadas, porém livre de geada.

Dada a facilidade de hibridação do gênero Mentha não se recomenda o plantio de diversas espécies de hortelã, lado a lado. São invasoras, de modo que devem ser plantadas de forma que possam ser contidas. A menta mais comum no Brasil em hortas e jardins, e bem adaptada nos trópicos e subtrópicos, pertence a Mentha piperita.

O tomilho é um subarbusto compacto, que cresce no máximo $25 \mathrm{~cm}$, de hastes eretas, com numerosas folhas pequenas. Já o tomilho limão, mais alto que o anterior, de folhas mais estreitas, apresenta aroma de limão. Em climas tropicais quentes não floresce. Desenvolve-se bem em climas temperados e subtropicais com bastante sol.

Em um jardim onde são entremeadas as ervas e especiarias, poderão ser incluídas plantas herbáceas de porte mais desenvolvido, tais como o gengibre e a curcuma, além de árvores de pequeno porte como o louro, o urucum e a aroeira vermelha ou pimenteira rosa. Esta vem sendo utilizada pelos frutos com sabor de pimenta suave. Entre as arbóreas de maior porte, a canela é bem conhecida. A pimenta da Jamaica, também arbórea, e a pimenta-do-reino, trepadeira, exigem clima quente e úmido. 
GIACOMETTI (1989) enfatiza que uma área grande de plantas da mesma espécie pode facilitar o surgimento e rápido desenvolvimento de pragas e doenças. A consorciação de duas ou mais espécies reduz este risco. Entretanto, é necessário, fazer um planejamento desta consorciação por causa dos efeitos alelopáticos (ação de uma espécie sobre o desenvolvimento da outra). Certas plantas ajudam-se, enquanto outras não se desenvolvem se colocadas juntas. A manjerona melhora o aroma das plantas. O alecrim é planta companheira da sálvia. A hortelã repele lepidópteros podendo ser plantada como bordadura de canteiros, exigindo, contudo atenção, pois se alastra com facilidade. Algumas associações devem ser evitadas - o funcho não se dá bem com nenhuma planta; a alfavaca não deve ser plantada perto da arruda.

A arruda e a mostarda, entre outras, atuam no controle natural de pragas, item muito importante, uma vez que resíduos danosos de inseticidas devem ser evitados em plantas utilizadas na preparação de alimentos. As folhas de arruda são utilizadas no preparo de uma infusão para o combate a pulgões. Dos frutos de pimenta-do-reino se extrai uma substância que inibe o consumo das plantas por diversos insetos.

As aromáticas, em sua maioria, são semeadas. Assim ocorre com a salsa, funcho, coentro. Já o tomilho, alecrim, hortelã e manjericão propagam-se também por estacas. A divisão de touceiras pode ser empregada na manjerona e estragão. Esse pode ser propagado também por meio de estacas com folhas, postas a enraizar na areia. $\mathrm{O}$ tomilho pode ser plantado a partir de seções enraizadas da planta. O poejo é propagado por divisão de estolões, assim como as espécies de hortelã-pimenta que não produzem sementes. O louro não frutifica no Brasil, sendo usada a alporquia.

Um espaço com temperos frescos pode também ser sinônimo de sofisticação. As aromáticas se integram facilmente a um projeto paisagístico. Idéias criativas e fáceis de realizar para atender a quem aprecia cultivá-las, mas não dispõe de muito espaço, serão apresentadas no decorrer da palestra. A escolha cuidadosa das plantas e seu posicionamento, no canteiro ou em recipientes, permitirão criar um conjunto harmonioso por si ou pela integração com outras plantas do jardim.

As ervas aromáticas e as especiarias perfumam e enfeitam, além de darem o arremate às receitas e um toque especial aos pratos. Tudo isto em seu próprio jardim! Um presente para todos os sentidos!

\section{BIBLIOGRAFIA CONSULTADA}

CORREA JUNIOR, C., CHAUMING, L., SCHEFFER, M.C. Cultivo de plantas medicinais, condimentares e aromáticas. 2. ed. Jaboticabal: FUNEP, 1994. 162 p.

DOYAMA, J.T., CASALI, V.W.D. (consultores técnicos). Plantas aromáticas e condimentares. Boletim Agropecuário Universidade Federal de Lavras. Lavras, n. 62, p. 1-83, 2005.

GIACOMETTI, D.C. Ervas condimentares e especiarias. São Paulo: Nobel, 1989. 158 p.

PAVEY, G. A. Jardins de Ervas. São Paulo: Nobel, 1998. 48p.

PAWEL, I., CHRISTOFFELS, G. Herbs - healthy lives with herbs from your own garden. Cape Town: Struik Publishers, 2006. 160 p.

RODWAY, A. Hierbas y especias: el cultivo y la utilización de las plantas más interesantes producidas por la naturaleza. Barcelona: Instituto Parragón Ediciones S.A, 1980. 159p.

STODOLA, J. \& VOLÁK, J. In: BUNNEY, S. (ed.) The illustrated Encyclopedia of Herbs - their medicinal and culinary uses. Cidade: Barnes \& Noble Books, 1990.320p. Wikipédia commons.wikimedia.org/wiki/File:Illustration_. 